\title{
Prevalence of Disrespect and Abuse and its Determinants during Antenatal Care Services in Rural Uttar Pradesh India
}

\author{
Akhilesh Yadav', T.B. Singh², Shikha Sachan ${ }^{3}$ \\ ${ }^{1}$ Doctoral Fellow, Institute of Medical Sciences, Banaras Hindu University, Varanasi-221005, India. \\ ${ }^{2}$ Professor, Centre of Biostatistics, Institute of Medical Sciences, Banaras Hindu University, Varanasi-221005, \\ India. \\ ${ }^{3}$ Assistant Professor, Dept. of Obstetrics and Gynaecology, Institute of Medical Sciences, Banaras Hindu \\ University, Varanasi-221005, India. \\ Corresponding Author: Akhilesh Yadav
}

DOI: https://doi.org/10.52403/ijhsr.20220216

\begin{abstract}
Background: Respectful maternity care is essential to increase safe motherhood, linked with increased maternal health services utilization, such as ANC (Antenatal Care). However, disrespect and abuse during maternal health care service utilisation remain a potential barrier to improve service utilisation and the quality of services.

Objective: This study aims to estimate the prevalence of disrespect and abuse (D\&VA) during the utilisation of ANC services and identifies the associated factors.

Methodology: A community based cross-sectional survey was conducted in the Balarampur district of Uttar Pradesh, India. The study included 364 women who underwent facility-based childbirth before six months of the survey. A multistage cluster sampling was used to select the potential participants of the study.

Results: the findings of the study show that nearly $60 \%$ of women experienced disrespect and abuse during ANC services utilisation. About $18 \%$ of women reported that the health providers were rude to them. Also, $1.5 \%$ of women reported that health providers used abusive language during the ANC services utilisation. Women aged 25-34 years and 35 and above years were $54 \%$ and $69 \%$ less likely to experience disrespect and abuse respectively than women aged 15-24 Years. Low odds of disrespect and abuse was observed with other backward, and General caste than the women belong to Scheduled tribe/caste. Women who experience disrespect and abuse during ANC services were less likely to receive all four types of ANC services.

Conclusions: Every woman has the right to receive kind and respectful maternity care, and mistreatment during maternal care services remains hindrances to achieving safe motherhood and child care.
\end{abstract}

Keywords: Disrespect and Abuse, Maternity Care, Antenatal Care Services, India.

\section{INTRODUCTION}

Despite global progress in reducing maternal mortality, the Low and MiddleIncome Countries (LMICs) account for most maternal death [1]. In order to increase safe motherhood, various stakeholder proposed to increase utilisation of maternal health services, including increasing the level of ANC (Antenatal care) services. Antenatal care services ensure early detection and management of pregnancy complications, preventing maternal morbidity and mortality [2]. ANC services' quality also includes positive care besides including only essential services [3]. Respectful maternity care is an integrated 
dimension of quality of care. A growing body of research worldwide found disrespect and abuse during maternal health service utilisation as a potential barrier in achieving safe motherhood [4]-[5].

The concept of 'respectful maternity care' is complicated to measure since it is majorly dependent on women's perceptions of who seek maternity care [6]. Respectful maternity care can be defined as 'treating a woman with dignity throughout her pregnancy, and childbirth period. It respects her rights and choices through supportive communication, actions and attitudes. Unfortunately, many studies worldwide show several incidences of maltreatment, including disrespect and abuse to women during birth delivery at health care facilities by health care providers. Maltreatment also includes physical abuse, disrespect, lack of privacy, consent care, rough handling and discrimination based on specific attributes [7], [8]. The prevalence of disrespect and abuse varies from $15 \%$ to $98 \%$ worldwide [9]-[11]. Due to the incident of disrespect and abuse during motherhood the moments which should be memorable becomes a nightmare for some women. Moreover, at least every third woman who opts for intuitional delivery experienced such a traumatic event [12].

Like any other LMICs, studies reported the prevalence of disrespect during maternity care in India as well. In a systematic review and meta-analysis, the prevalence of disrespectful maternity care is found $71.31 \%$ in the Indian subcontinent [13]. Moreover, abuse during labour found very common in the metro cities in India, which diminishes the future possibility of treatment-seeking among mothers [13]. One such study based on cross-sectional data including both observational and selfreported cases in rural Uttar Pradesh revealed that out of the 17 items listed in the study, $77.3 \%$ of the study participants reported mistreatment and disrespect in at least one of the categories [14].

The incidents of disrespect and abuse are not limited to institutional delivery. For example, studies show that a significant proportion of women suffers disrespect and abuse during their antenatal [15], [16]. A study based in Ethiopia shows a $65 \%$ prevalence of disrespect and abuse during ANC follow up before the intervention [17]. At the same time, the previous experience of disrespect and abuse at a facility can prevent women from adopting further maternal and child health care services, including institutional delivery [18]-[21].

A few studies conducted in recent years expanded our understanding of factor associated with respectful maternity care. Women's demographic and socioeconomic factors, including women's age, caste, and parity, were associated with disrespect and abuse during maternal service utilisation [22]. Evidence also suggests that women's education and economic status were associated with disrespect and abuse during maternity care [23]. Evidence from the literature suggests that disrespect and abuse during the maternity care utilisation were incredibly more among economically weak, younger, or have children with disabilities [24].

Disrespect and abuse during childbirth in health facilities is a burning issue worldwide and emerged as a common problem in maternal health care. It is contributing to untold suffering and discouraging women from seeking maternal care at health facilities. However, such association is limited in the Indian context, and further investigation is vital to broadening our standing of the issue. Therefore, with the prime objective, we aim to estimate the prevalence of disrespect and abuse during antenatal care visits and explore the associated factors in the Balrampur district of Uttar Pradesh in India, characterised as high maternal mortality in India.

\section{DATA AND METHODOLOGY}

A community-based cross-sectional study was conducted in two blocks of Balrampur district, Uttar Pradesh, India. A 
single population proportion formula was used to estimate the sample for the study. The expected level of disrespect and abuse of $28.8 \%$ (excluding inappropriate money demand due to its high prevalence was 90.5\%). (Bhattacharya, 2018), $95 \%$ of confidence interval,7\% precision, and $20 \%$ non-response rate were used to calculate the sample size of 384 . The study included 384 women using the multistage cluster sampling who underwent facility-based childbirth during the last six months before the survey. Out of 384 women, 20 respondents did not receive any ANC services before the delivery; hence, the study is based on 364 respondents.

\section{Ethical Approval}

Ethical Clearance was obtained from the "Ethical Review Committee" of the Institute of Medical Sciences, Banaras Hind University, Varanasi. Respondents have explained the aim and the purpose of the study, and the interview began with written consent from each respondent.

\section{Data collection tool}

A pre-tested semi-structured schedule was used for data collection collect data. The questionnaire was prepared in English and Hindi both. Face to face interviews was conducted between April to September 2019.

\section{Variables}

\section{Dependent Variable}

Women were asked a set of different questions on Disrespect and abuse (D\&A), including physical abuse, non-consent care, and non-confidential care during ANC. The dependent variable was coded dichotomous "any disrespect and abuse $=1$ " if women experienced at least one type of disrespect or abuse and " $0=$ if she does not experience any incident of D\&A during ANC visit".

Other dependent variables were defined as "complete ANC $=1$ " if women receive at least four ANC services or " 0 if they received less than four ANC services" to explore the impact of D\&A on Complete ANC services.

\section{Independent Variable}

This study includes various sociodemographic variables like Present age, education, partner's education, caste, religion, wealth quintile of the respondent, Time of ANC registration, no. of ANC visits.

\section{Data analysis}

The characteristics of the study population were summarised by computing univariate analysis. Bivariate analysis was conducted for the prevalence of D\&A by the background characteristics of respondents. We also computed the Chi-square Test of association to examine the relationship between D\&A and independent variable. Finally, determinants of D\&A was examined by performing a Binary logistic regression analysis of different background characteristics for the study population.

If $\mathrm{Yi}$ is the dependent variable, $\mathrm{Xi}$ is a set of explanatory variables, and $\beta i$ 's are the coefficient, then the logistic regression equation is

$$
\operatorname{logit}(P)=\log \left(\frac{p}{1-p}\right)=\beta_{0}+\beta_{1} X_{1}+\beta_{2} X_{2}+\cdots \varepsilon
$$

Where $\mathrm{p}$ predicts the probability and $\log$ odds of $\mathrm{p}$ and $(1-\mathrm{p})$ provide the odds ratios on the reference category. Data were analysed using SPSS trail Version 25.

\section{RESULTS}

\section{Background characteristics of the study Subjects}

Nearly $27 \%$ of respondents were aged between 15-24 years, and about the three fifth i.e , $60 \%(n=220)$, were aged 2534 years, and $12 \%$ were above 34 years. Nearly $14 \%$ of women were married before the legal marriage age for girls is 18 years, and $85.7 \%$ of them were married after the legal age of marriage. Three-fourths of the study population were Hindus, whereas onefourth of the respondents were from the others religion. Women representing the 
Akhilesh Yadav et.al. Prevalence of disrespect and abuse and its determinants during antenatal care services in Rural Uttar Pradesh India.

general caste were $34.8 \%$, followed by $33 \%$ $\mathrm{SC} / \mathrm{ST}$, and $32 \%$ from Other backward caste. A significant proportion of women (72\%) had no formal schooling, $15 \%$ had primary, and $13 \%$ had a secondary or above level of schooling. A less than half of women's husbands $(45 \%)$ were illiterate. On the other hand, about $27 \%$ of them had up to a primary or secondary and above level of education. Out of the total, 235 (65 $\%)$ respondents were homemaker, and the rest were engaged in some economic activity. Around three-fourths of respondents $(n=266)$ lived in joint family systems, and the remaining $(\mathrm{n}=98)$ lived as a nuclear family. A less than quarter of women $(21 \%)$ were belonged to the poorest wealth quintile, followed by middle $(20 \%)$, rich $(20 \%)$, richest $(19 \%)$ wealth quintile. More than half $(51 \%)$ of the respondents were registered within the first trimester during the last pregnancy. However, only one-third of them $(n=122)$ had received all four antenatal care services, and $66 \%$ $(n=242)$ of them have received less than four antenatal care services.
Table 1.: Percentage distribution of respondent by their background characteristics

\begin{tabular}{|c|c|c|}
\hline Socio-demographic & Frequency & Percentage \\
\hline \multicolumn{3}{|l|}{ Age Group } \\
\hline $15-24$ & 99 & 27.20 \\
\hline $25-34$ & 220 & 60.44 \\
\hline 35 and above & 45 & 12.36 \\
\hline \multicolumn{3}{|l|}{ Age at Marriage } \\
\hline less than 18 years & 52 & 14.29 \\
\hline 18 and above & 312 & 85.71 \\
\hline \multicolumn{3}{|l|}{ Religion } \\
\hline Hindu & 273 & 75.00 \\
\hline Muslim & 91 & 25.00 \\
\hline \multicolumn{3}{|l|}{ Caste } \\
\hline SC/ST & 120 & 32.97 \\
\hline $\mathrm{OBC}$ & 117 & 32.14 \\
\hline General & 127 & 34.89 \\
\hline \multicolumn{3}{|l|}{ Education level } \\
\hline no formal education & 264 & 72.53 \\
\hline primary & 53 & 14.56 \\
\hline secondary and above & 47 & 12.91 \\
\hline \multicolumn{3}{|c|}{ Husband education level } \\
\hline no formal education & 163 & 44.78 \\
\hline primary & 100 & 27.47 \\
\hline secondary and above & 101 & 27.75 \\
\hline \multicolumn{3}{|l|}{ Occupation } \\
\hline home maker & 235 & 64.56 \\
\hline other & 129 & 35.44 \\
\hline \multicolumn{3}{|l|}{ Family Type } \\
\hline joint & 266 & 73.08 \\
\hline Nuclear & 98 & 26.92 \\
\hline \multicolumn{3}{|l|}{ Wealth Index } \\
\hline Poorest & 77 & 21.15 \\
\hline Poor & 70 & 19.23 \\
\hline Middle & 75 & 20.60 \\
\hline Rich & 73 & 20.05 \\
\hline Richest & 69 & 18.96 \\
\hline \multicolumn{3}{|l|}{ Time of Registration } \\
\hline Within 12 weeks & 186 & 51.10 \\
\hline After 12 weeks & 178 & 48.90 \\
\hline \multicolumn{3}{|l|}{$4 \mathrm{ANC}$} \\
\hline 4and above & 122 & 33.52 \\
\hline less than 4 ANC & 242 & 66.48 \\
\hline
\end{tabular}

Survey 2015-16.

\section{Prevalence of disrespectful Maternity care during ANC}

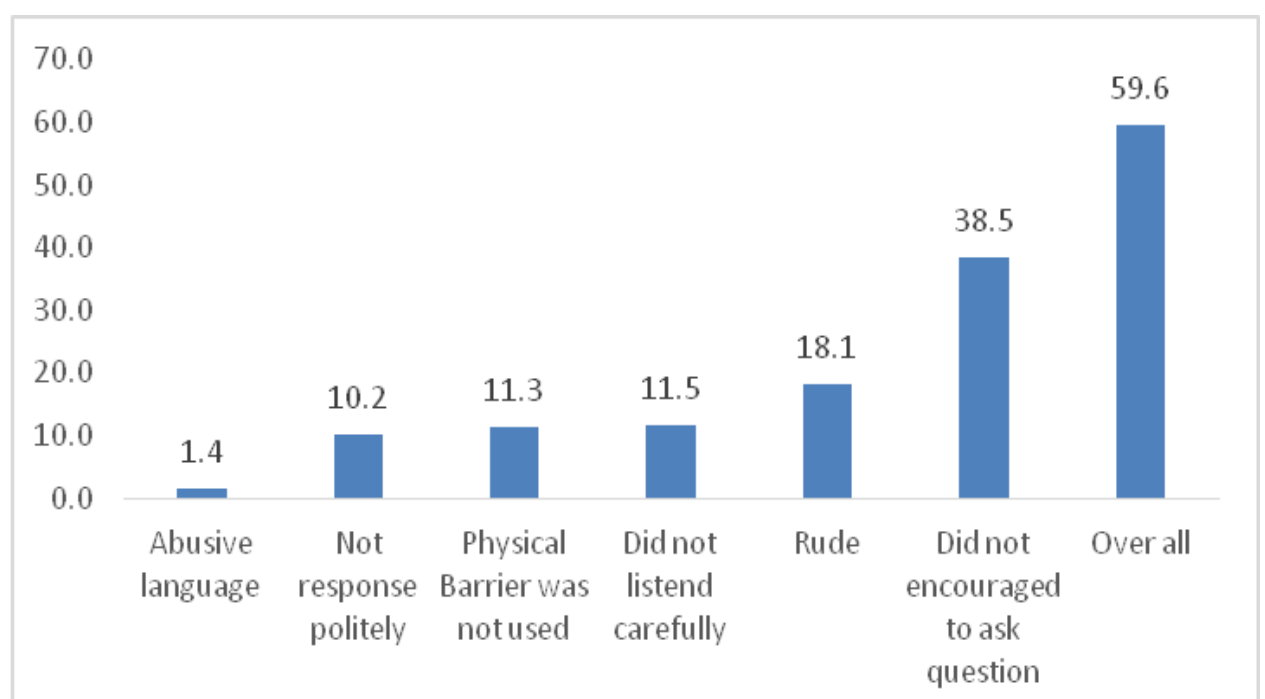

Figure 1: Percentage of type of disrespect and abuse experienced by respondents during Antenatal care visit 
Figure 1 shows the prevalence of different kind of disrespect and abuse during ANC services. More than half $(59.6 \%)$ of the respondents experienced at least one forms of abuse or disrespect at the time of antenatal care services. In $1.4 \%$ of cases, women tolerated abusive language from the service providers, and $18 \%$ of them reported that the service providers were impolite. Out of the total women, 140 reported that they were not encouraged to ask any question regarding pregnancy and maternal care. About $11.5 \%$ of women felt that the doctors/providers were not listening carefully. One out of every ten women did not receive a polite response from a service provider. The use of physical barrier during antenatal services is compulsory; however, $11.3 \%$ of women reported non-use of barriers during the ANC's services.

Table 2 represents the association between abuse and disrespect with selected socioeconomic and demographic characteristics of women. Out of the total, $72 \%$ of women in the age group 15-24 years had encountered abuse and disrespect during ANCs service utilisation, followed by women in the age group 25-34 (55\%). Also, $45 \%$ of women aged 35 and above experience D\&A during ANC services. The prevalence of D\&A during ANCs was 63\% and $59 \%$ among women who were less than 18 or at least 18 years at the time of marriage. The percentage of D\&A during ANC services found $58 \%$ among Hindu and $65 \%$ among women, who belongs to Other religion. We also analyse the prevalence of D\&A by caste and results show that $72 \%$ of women who belong to scheduled caste/scheduled tribe experienced D\&A, and $56 \%$ and $52 \%$ among women who belonged to 'Other backward class' and 'General' caste respectably. Furthermore, the percentage of D\&A was higher among illiterate women $(62 \%)$, followed by women having primary education $(58 \%)$ and secondary or above education (53\%). Noticeably, the prevalence of D\&A was 67 $\%$, among working women than women who were homemakers $55 \%$. The percentage of disrespect and abuse was $63 \%$, and $70 \%$ among women belonged to the middle and rich wealth quintile, and the prevalence of D\&A was lowest among women belonging to the poor wealth quintile.

Table 2: Abuse and disrespect during ANC and its Association with various socio -demographic and Obstetric Variables \begin{tabular}{|l|l|l|l|}
\hline Socio-demographic & $\%$ of any abuse during & Chi & P-
\end{tabular}

\begin{tabular}{|c|c|c|c|}
\hline socio-cemograpmic & ANC & & value \\
\hline \multicolumn{4}{|l|}{ Age Group } \\
\hline $15-24$ & 71.72 & \multirow[t]{3}{*}{8.34} & \multirow[t]{3}{*}{0.015} \\
\hline $25-34$ & 55.45 & & \\
\hline 35 and above & 45.28 & & \\
\hline \multicolumn{4}{|l|}{ Age at Marriage } \\
\hline less than 18 years & 63.46 & \multirow[t]{2}{*}{0.37} & \multirow{2}{*}{0.542} \\
\hline 18 and above & 58.97 & & \\
\hline \multicolumn{4}{|l|}{ Religion } \\
\hline Hindu & 57.88 & \multirow[t]{2}{*}{1.37} & \multirow[t]{2}{*}{0.241} \\
\hline Muslim & 64.84 & & \\
\hline \multicolumn{4}{|l|}{ Caste } \\
\hline $\mathrm{SC} / \mathrm{ST}$ & 71.67 & \multirow{3}{*}{$\begin{array}{l}11.1 \\
2\end{array}$} & \multirow[t]{3}{*}{0.004} \\
\hline OBC & 55.56 & & \\
\hline General & 51.97 & & \\
\hline \multicolumn{4}{|l|}{$\begin{array}{l}\text { Respondent's } \\
\text { education }\end{array}$} \\
\hline no formal education & 60.98 & \multirow[t]{3}{*}{1.04} & \multirow[t]{3}{*}{0.595} \\
\hline primary & 58.49 & & \\
\hline $\begin{array}{l}\text { secondary and } \\
\text { above }\end{array}$ & 53.19 & & \\
\hline \multicolumn{4}{|l|}{$\begin{array}{l}\text { Husband's } \\
\text { education }\end{array}$} \\
\hline no formal education & 58.90 & \multirow[t]{3}{*}{0.71} & \multirow[t]{3}{*}{0.700} \\
\hline primary & 63.00 & & \\
\hline $\begin{array}{l}\text { secondary and } \\
\text { above }\end{array}$ & 57.43 & & \\
\hline \multicolumn{4}{|l|}{ Occupation } \\
\hline home maker & 55.32 & \multirow[t]{2}{*}{5.08} & \multirow[t]{2}{*}{0.024} \\
\hline other & 67.44 & & \\
\hline \multicolumn{4}{|l|}{ Family Type } \\
\hline joint & 59.77 & \multirow[t]{2}{*}{0.01} & \multirow[t]{2}{*}{0.919} \\
\hline Nuclear & 59.18 & & \\
\hline \multicolumn{4}{|l|}{ Wealth Index } \\
\hline Poorest & 51.95 & \multirow[t]{5}{*}{6.18} & \multirow[t]{5}{*}{0.186} \\
\hline Poorer & 54.29 & & \\
\hline Middle & 62.67 & & \\
\hline Richer & 69.86 & & \\
\hline Richest & 59.42 & & \\
\hline $\begin{array}{ll}\text { Time } & \text { of } \\
\text { Registration }\end{array}$ & & & \\
\hline Within 12 weeks & 59.14 & 0.03 & 0.850 \\
\hline After 12 weeks & 60.11 & 6 & \\
\hline $4 \mathrm{ANC}$ & & & \\
\hline 4 and above & 48.36 & 9.65 & 0.002 \\
\hline less than $4 \mathrm{ANC}$ & 65.29 & & \\
\hline
\end{tabular}

\section{Factor Associated with disrespect and abuse during ANC services}

Binary logistic regression was performed to assess the association of each independent variable with abuse and disrespect and illustrated in table 3 . Women in the age group 25-34 years and 35+ years 
were $55 \%$ and $(70 \%)$ were less likely to experience disrespect and abuse respectively than the respondent in the age group of 1524 years. Respondents who were married after the legal age of marriage, 18 years and above, were $53 \%$ less likely to experience abuse and disrespect than the respondent who married before age 18 years. Women belonged to the General caste were 0.51 times less likely to experience D\&A than women who belonged to the SC/ST caste.

Table 3: Result of logistic regression of abuse \& disrespect and socio demographic characteristics

\begin{tabular}{|c|c|c|c|c|}
\hline \multirow[t]{2}{*}{ Socio-demographic } & \multicolumn{2}{|c|}{ Unadjusted odds ratio } & \multicolumn{2}{|c|}{ Adjusted odds ratio } \\
\hline & OR & P Value & OR & P Value \\
\hline \multicolumn{5}{|l|}{ Age Group } \\
\hline \multicolumn{5}{|l|}{$15-24 ®$} \\
\hline $25-34$ & $0.491 * * *$ & 0.006 & $0.453 * * *$ & 0.006 \\
\hline 35 and above & $0.451 * * *$ & 0.033 & $0.299 * * *$ & 0.005 \\
\hline \multicolumn{5}{|l|}{ Age at Marriage } \\
\hline \multicolumn{5}{|l|}{ less than 18 years ${ }^{\circledR}$} \\
\hline 18 and above & 0.828 & 0.542 & $0.467 * *$ & 0.033 \\
\hline \multicolumn{5}{|l|}{ Religion } \\
\hline \multicolumn{5}{|l|}{ Hindu $®$} \\
\hline Muslim & 1.340 & 0.242 & 1.563 & 0.113 \\
\hline \multicolumn{5}{|l|}{ Caste } \\
\hline \multicolumn{5}{|l|}{ SC/ST } \\
\hline $\mathrm{OBC}$ & $0.494 * *$ & 0.01 & 0.651 & 0.174 \\
\hline General & $0.428 * * *$ & 0.002 & $0.506^{* * *}$ & 0.035 \\
\hline \multicolumn{5}{|l|}{ Women's Education } \\
\hline \multicolumn{5}{|l|}{ no formal education $\AA$} \\
\hline primary & 0.901 & 0.735 & 0.776 & 0.477 \\
\hline secondary and above & 0.727 & 0.317 & 0.653 & 0.329 \\
\hline \multicolumn{5}{|l|}{ Husband's Education } \\
\hline \multicolumn{5}{|l|}{ no formal education ${ }^{\circledR}$} \\
\hline primary & 1.188 & 0.509 & 1.146 & 0.639 \\
\hline secondary and above & 0.941 & 0.814 & 1.159 & 0.654 \\
\hline \multicolumn{5}{|l|}{ Occupation } \\
\hline \multicolumn{5}{|l|}{ home maker® } \\
\hline other & 1.673 & 0.025 & 1.506 & 0.141 \\
\hline \multicolumn{5}{|l|}{ Family Type } \\
\hline \multicolumn{5}{|l|}{ joint $\AA$} \\
\hline Nuclear & 0.975 & 0.919 & 1.132 & 0.645 \\
\hline \multicolumn{5}{|l|}{ Wealth Index } \\
\hline \multicolumn{5}{|l|}{ Lowest $\AA$} \\
\hline Second & 1.098 & 0.777 & 0.923 & 0.827 \\
\hline Middle & 1.553 & 0.183 & 1.460 & 0.304 \\
\hline Fourth & 2.144 & 0.026 & 1.815 & 0.126 \\
\hline Highest & 1.354 & 0.365 & 1.050 & 0.907 \\
\hline \multicolumn{5}{|l|}{ Time of Registration } \\
\hline \multicolumn{5}{|l|}{ Within 12 weeks $®$} \\
\hline After 12 weeks & 1.041 & 0.850 & 0.947 & 0.823 \\
\hline \multicolumn{5}{|l|}{$4 \mathrm{ANC}$} \\
\hline \multicolumn{5}{|l|}{4 and above } \\
\hline less than 4 ANC & 2.008 & 0.002 & 2.080 & 0.003 \\
\hline _cons & & & 4.708 & 0.004 \\
\hline
\end{tabular}

Religion, respondent education, quantile, and early registration during husband education, occupation of the pregnancy were not significantly associated respondent, type of family, the wealth with the experience of disrespect and abuse.

The association between women experience D \&A during ANC and their complete ANC visit

Table 4: Percentage of complete ANC services and it's association with experience of disrespect and abuse

\begin{tabular}{|l|l|l|l|l|l|}
\hline \multirow{2}{*}{ Experience any abuse } & \multicolumn{3}{|c|}{ Unadjusted odds ratio } & \multicolumn{2}{|c|}{ Adjusted odds ratio } \\
\cline { 2 - 6 } & \% of four ANC & OR & P Value & OR & P Value \\
\hline No & 42.86 & & & & \\
\hline Yes & 27.19 & $0.498^{* * *} *$ & 0.002 & $0.524 * * *$ & 0.008 \\
\hline
\end{tabular}


Table 4 shows that the prevalence of complete ANCs was low among the study participants. Around $34 \%$ of women received all four ANC services. The prevalence of complete ANC was $42 \%$ among women who did not experience disrespect and abuse, and it was $28 \%$ among women who experience any disrespect or abuse during their ANC visits. The results from logistic regression suggest that the odds of receiving all four ANC services were $50 \%$ [AOR $=0.50, p=0.001]$ less among women who experienced any disrespect or abuse during ANC services than women who did not experience D\&A.

\section{DISCUSSION}

This study estimated the prevalence of disrespect and abuse during ANC and explored its associated factors. In the study population, every second woman reported at least one kind of abuse and disrespect during ANC services utilisation. This proportion is slightly lower than the previous study conducted in the Northwest of Ethiopia, which shows the prevalence of disrespect or abuse during ANC services $71.8 \%$ before intervention [17]. In contrast, the rate is comparatively higher than the previous study conducted in six European countries in which was $20 \%$ [15]. However, a study reported a lower prevalence than the prevalence of disrespect and abuse during childbirth conducted in Aligarh, North India, which estimated that $84.3 \%$ of rural women experienced disrespect during facility-based childbirth [25].

The current study also explored the factor associated with disrespect or abuse during antenatal care services in India. Women's age was associated with the D\&A, and older women were less likely to experience any disrespect or abuse during ANC services, consistent with the findings from other studies [22], [24]. The analysis also concludes that women who belonged to the 'General' caste group were less likely to experience any disrespect or abuse during ANC service than women from the ST/SC. Scholars documents differential in treatment against SC/ST population in India[26]-[28]. Scheduled caste populations experienced more apathy, denial, and negligence from service providers, especially in rural India[29].

A previous study found that women in high-income groups were less likely to experience disrespect [10], [23]. Studies also found lower odds of experiencing disrespect and abuse with the women's better educational level. However, our study did not find a significant association between D\&A and women's education and economic status. Husband's education was also not found significantly associated with the women's experience of disrespect and abuse; this may be because men are often excluded from routine care in India and do not accompany their wife during ANC services [30].

Our study also found low odds of receiving complete antenatal care services associated with the women experience of disrespect during ANC services. Studies from other parts of the world also suggest that one of every four women who avoid ANC service has been disrespected by health care providers [31]. Antenatal services are essential for save motherhood and have been proven vital elements to reduce maternal and child mortality. Various stakeholders also recommend at least four ANC visits for safe motherhood and child health[32], [33]. Despite this recommendation, various factor prevents women from receiving ANCs services, and one of them is the disrespect or abuse during the health care services utilisation.

Every woman has the right to receive respectful maternity care, and mistreatment during maternal care services hinders achieving safe motherhood and child care. Therefore, maternal health efforts should focus on improving the quality of care to improve service utilisation. Studies suggest that the frequent training program and written procedure and guideline and monitoring system among healthcare providers can improve respectful maternity care[19]. Therefore, we 
recommend tailored interventions, policies and programmes for various dynamic systems and regular monitoring and evaluation for achieving respectful maternity care in India.

\section{Strength of the study}

The study's strength includes the fact that it was performed in a community setting that provides more external validation than a study conducted in a hospital. As a result, women might be more willing to express traumatic events at home than in a facility. Moreover, the study was carried out on women who already delivered babies 4-6 weeks before, significantly reducing recall bias and cutting down the stress level. Disrespect and abuse during ANC services in India is undoubtedly a significant problem, especially in the rural parts of the country, which needs to be resolved to enhance maternal care and obstetric services and recognise every woman's right to seek respectful health care services. More mixed-method studies are required to understand the dynamics involved in such experiences.

\section{Limitation of the Study}

This study includes women who gave childbirth at a health facility before six months of the survey. However, the incident of disrespect or abuse during ANC service can not only prevent women from completing all ANC visits but can also prevent her from opting facility-based. Since this study include only those women who gave childbirth at health facility before six months of the survey, it has limitation to explore it.

\section{Acknowledgement: None}

\section{Conflict of Interest: None}

Source of Funding: None

Ethical Approval: Approved

\section{REFERENCES}

1. [WHO, "Trends in Maternal Mortality: 2000 to 2017," 2019. /featuredpublication/trends-maternal-mortality-20002017 (accessed May 28, 2021).

2. M. Bauserman et al., "Risk factors for maternal death and trends in maternal mortality in low- and middle-income countries: a prospective longitudinal cohort analysis," Reprod. Health, vol. 12 Suppl 2, p. S5, 2015, doi: 10.1186/1742-4755-12-S2S5.

3. N. R. van den Broek and W. J. Graham, "Quality of care for maternal and newborn health: the neglected agenda," BJOG Int. J. Obstet. Gynaecol., vol. 116 Suppl 1, pp. 1821 , Oct. 2009, doi: 10.1111/j.14710528.2009.02333.x.

4. A. Asefa, "Unveiling respectful maternity care as a way to address global inequities in maternal health," BMJ Glob. Health, vol. 6, no. 1, Jan. 2021, doi: 10.1136/bmjgh-2020003559.

5. C. H. Morton and P. Simkin, "Can respectful maternity care save and improve lives?," Birth Berkeley Calif, vol. 46, no. 3, pp. 391-395, Sep. 2019, doi: 10.1111/birt.12444.

6. M. W. Gebremichael, A. Worku, A. A. Medhanyie, and Y. Berhane, "Mothers' experience of disrespect and abuse during maternity care in northern Ethiopia," Glob. Health Action, vol. 11, no. 1, p. 1465215, Jan. 2018, doi: 10.1080/16549716.2018.1465215.

7. R. Jewkes, N. Abrahams, and Z. Mvo, "Why do nurses abuse patients? Reflections from South African obstetric services," Soc. Sci. Med., vol. 47, no. 11, pp. 1781-1795, Dec. 1998, doi: 10.1016/S02779536(98)00240-8.

8. D. Bowser and K. Hill, "Exploring Evidence for Disrespect and Abuse in Facility-Based Childbirth," p. 57, 2010.

9. Z. Y. Kassa and S. Husen, "Disrespectful and abusive behavior during childbirth and maternity care in Ethiopia: a systematic review and meta-analysis," BMC Res. Notes, vol. 12, Feb. 2019, doi: 10.1186/s13104-019-4118-2.

10. T. Abuya et al., "Exploring the Prevalence of Disrespect and Abuse during Childbirth in Kenya," PLOS ONE, vol. 10, no. 4, p. e0123606, Apr. 2015, doi: 10.1371/journal.pone.0123606. 
11. B. Wassihun, L. Deribe, N. Worede, and T. Gultie, "Prevalence of disrespect and abuse of women during child birth and associated factors in Bahir Dar town, Ethiopia," Epidemiol. Health, vol. 40, Jul. 2018, doi: 10.4178/epih.e2018029.

12. P. A. Afulani and C. A. Moyer, "Accountability for respectful maternity care," Lancet Lond. Engl., vol. 394, no. 10210, pp. 1692-1693, Nov. 2019, doi: 10.1016/S0140-6736(19)32258-5.

13. A. Singh, M. Chhugani, and M. James, "Direct Observation on Respectful Maternity Care in India: A Cross Sectional Study on Health Professionals of three different Health Facilities in New Delhi," Int. J. Sci. Res., vol. 7, no. 5, pp. 821-825, 2018. doi: $10.21275 /$ ART20182649.

14. A. Dey et al., "Discordance in self-report and observation data on mistreatment of women by providers during childbirth in Uttar," pp. 1-13, 2017, doi: 10.1186/s12978-017-0409-z.

15. M. Lukasse et al., "Prevalence of experienced abuse in healthcare and associated obstetric characteristics in six European countries," Acta Obstet. Gynecol. Scand., vol. 94, no. 5, pp. 508-517, May 2015, doi: 10.1111/aogs.12593.

16. J. Gouda and C. Shekhar, "How respectfully women are treated during difficult phase like childbirth? A primary survey of differently-managed health facilities in Odisha, India," Clin. Epidemiol. Glob. Health, vol. 8, no. 3, pp. 828-834, Sep. 2020, doi: 10.1016/j.cegh.2020.02.008.

17. H. Mihret, A. Atnafu, T. Gebremedhin, and E. Dellie, "Reducing Disrespect and Abuse of Women During Antenatal Care and Delivery Services at Injibara General Hospital, Northwest Ethiopia: A Pre-Post Interventional Study," Int. J. Womens Health, vol. 12, pp. 835-847, Oct. 2020, doi: 10.2147/IJWH.S273468.

18. C. R. Titaley, C. L. Hunter, M. J. Dibley, and P. Heywood, "Why do some women still prefer traditional birth attendants and home delivery?: a qualitative study on delivery care services in West Java Province, Indonesia," BMC Pregnancy Childbirth, vol. 10, no. 1, p. 43, Aug. 2010, doi: 10.1186/1471-2393-10-43.

19. M. A. Bohren, E. C. Hunter, H. M. MuntheKaas, J. P. Souza, J. P. Vogel, and A. M. Gülmezoglu, "Facilitators and barriers to facility-based delivery in low- and middleincome countries: a qualitative evidence synthesis," Reprod. Health, vol. 11, no. 1, p. 71, Sep. 2014, doi: 10.1186/1742-4755-1171.

20. E. Anastasi et al., "Losing women along the path to safe motherhood: why is there such a gap between women's use of antenatal care and skilled birth attendance? A mixed methods study in northern Uganda," $B M C$ Pregnancy Childbirth, vol. 15, no. 1, p. 287, Nov. 2015, doi: 10.1186/s12884-015-06959.

21. Y. Mehretie Adinew and N. Abera Assefa, "Experience of Facility Based Childbirth in Rural Ethiopia: An Exploratory Study of Women's Perspective," J. Pregnancy, vol. 2017, p. e7938371, Nov. 2017, doi: 10.1155/2017/7938371.

22. H. Ansari and R. Yeravdekar, "Respectful maternity care during childbirth in India: A systematic review and meta-analysis," $J$. Postgrad. Med., vol. 66, no. 3, pp. 133-140, 2020, doi: 10.4103/jpgm.JPGM_648_19.

23. P. Patel, K. Makadia, and geeta kedia, "Study to assess the extent of disrespect and abuse in facility based child birth among women residing in urban slum area of Ahmedabad," Int. J. Multidiscip. Res. Dev., vol. 2, no. 8, pp. 25-27, 2015.

24. A. M. L. Id et al., "Deliver on Your Own: Disrespectful Maternity Care in rural Kenya," pp. 1-16, 2020.

25. T. Nawab, U. Erum, A. Amir, N. Khalique, M. A. Ansari, and A. Chauhan, "Disrespect and abuse during facility-based childbirth and its sociodemographic determinants - A barrier to healthcare utilization in rural population," J. Fam. Med. Prim. Care, vol. 8, no. 1, pp. 239-245, Jan. 2019, doi: 10.4103/jfmpc.jfmpc_247_18.

26. S. s Acharya, "Caste and patterns of discrimination in rural public health care services," in In Thorat, S., Newman, K. S. (Eds.) Blocked by caste-Economic discrimination and social exclusion in modern India, Delhi: Oxford University Press, 2010, pp. 208-29.

27. G. Pal, "Caste and access to public services 'Intensified' disadvantages," Econ. Polit. Wkly., vol. 51, no. 31, pp. 102-107, Jul. 2016.

28. S. George, "Caste And Care: Is Indian Healthcare Delivery System Favourable For 
Dalits?," Inst. Soc. Econ. Change, p. 18, 2015.

29. S. George, "Reconciliations of Caste and Medical Power in Rural Public Health Services," Econ. Polit. Wkly., vol. 54, pp. 43-50, Oct. 2019.

30. A. Barua, R. P. Pande, K. MacQuarrie, and S. Walia, "Caring Men? Husbands' Involvement in Maternal Care of Young Wives," Econ. Polit. Wkly., vol. 39, no. 52, pp. 5661-5668, 2004.

31. P. Miller, P. A. Afulani, S. Musange, F. Sayingoza, and D. Walker, "Personcentered antenatal care and associated factors in Rwanda: a secondary analysis of program data," BMC Pregnancy Childbirth, vol. 21, no. 1, p. 290, Apr. 2021, doi: 10.1186/s12884-021-03747-z.

32. J. Villar et al., "WHO antenatal care randomised trial for the evaluation of a new model of routine antenatal care," Lancet Lond. Engl., vol. 357, no. 9268, pp. 15511564, May 2001, doi: 10.1016/s01406736(00)04722-x.

33. W. H. Organization, WHO antenatal care randomized trial: manual for the implementation of the new model. World Health Organization, 2002. Accessed: May 28, 2021. [Online]. Available: https://apps.who.int/iris/handle/10665/4251 3

How to cite this article: Yadav A, T.B. Singh, Sachan S. Prevalence of disrespect and abuse and its determinants during antenatal care services in Rural Uttar Pradesh India. Int $J$ Health Sci Res. 2022; 12(2): 115-124. DOI: https://doi.org/10.52403/ijhsr.20220216 